\title{
Incidence of symptomatic tethered spinal cord in pediatric patients presenting with neurofibromatosis types 1 and 2
}

\author{
Carolyn S. Quinsey, MD, Katie Krause, MD, PhD, Lissa C. Baird, MD, \\ Christina M. Sayama, MD, MPH, and Nathan R. Selden, MD, PhD \\ Department of Neurological Surgery and Doernbecher Children's Hospital, Oregon Health \& Science University,
Portland, Oregon
}

\begin{abstract}
OBJECTIVE The relationship between a tethered cord (TC) and neurofibromatosis type 1 (NF1) and NF2 is not known. The purpose of this study was to define the incidence of TC in pediatric neurosurgical patients who present with NF.

METHODS The authors performed a single-institution (tertiary care pediatric hospital) 10-year retrospective analysis of patients who were diagnosed with or who underwent surgery for a TC and/or NF. Clinical and radiological characteristics were analyzed, as was histopathology.

RESULTS A total of 424 patients underwent surgery for a TC during the study period, and 67 patients with NF were seen in the pediatric neurosurgery clinic. Of these 67 patients, $9(13 \%)$ were diagnosed with a TC, and filum lysis surgery was recommended. Among the 9 patients with NF recommended for TC-release surgery, $4(44 \%)$ were female, the mean age was 8 years (range $4-14$ years), the conus position ranged from L1-2 to L-3, and $3(33 \%)$ had a filum lipoma, defined as high signal intensity on T1-weighted MR images. All 9 of these patients presented with neuromotor, skeletal, voiding, and/or pain-related symptoms. Histopathological examination consistently revealed dense fibroconnective tissue and blood vessels.
\end{abstract}

CONCLUSIONS Despite the lack of any known pathophysiological relationship between NF and TC, the incidence of a symptomatic TC in patients with NF1 and NF2 who presented for any reason to this tertiary care pediatric neurosurgery clinic was $13 \%$. Counseling patients and families regarding TC symptomatology might be indicated in this patient population.

https://thejns.org/doi/abs/10.3171/2017.12.PEDS17306

KEY WORDS neurofibromatosis; tethered cord; filum lipoma; pediatric; spine

A TETHERED cord (TC) can be caused by an abnormally tight filum terminale and result in traction on the spinal cord and clinical symptomatology of TC syndrome, including back or lower-extremity pain, sensory and motor abnormalities, musculoskeletal deformity, and voiding dysfunction. Radiological hallmarks can include a low-lying conus medullaris and/or an abnormally thickened or fatty filum. ${ }^{9}$ The definitive treatment for symptomatic patients with filum tethering is surgical transection. ${ }^{8}$

Cutaneous findings, including large raised hemangiomata and sacral dimples, are associated with a higher risk for the presence of a TC. ${ }^{1,6,7}$ The incidence of a TC in patients with a neurocutaneous syndrome is not known. Neurofibromatosis type 1 (NF1) and NF2 are autosomal dominant neurocutaneous syndromes..$^{5} \mathrm{NF} 1$ is associated with spinal skeletal deformity but not with occult spinal dysraphism or spinal cord tethering. ${ }^{10}$

Based on observations of multiple patients with NF, abnormalities of the filum terminale, and cord tethering, we hypothesized that NF might be associated with an increased incidence of TC. The Division of Pediatric Neurosurgery at Oregon Health \& Science University (OHSU) serves as a major tertiary referral center at Oregon's only academic health center. A broad range of pediatric neurosurgical procedures are performed in this division (which currently employs 3 pediatric neurosurgeons); the volume in 2017 was 780 major operating room-based procedures and 800 clinic-based new patient referrals.

ABBREVIATIONS ICD-9 = International Classification of Diseases, Ninth Revision; NF = neurofibromatosis; $\mathrm{OHSU}=$ Oregon Health \& Science University; TC = tethered cord.

SUBMITTED June 5, 2017. ACCEPTED December 8, 2017.

INCLUDE WHEN CITING Published online February 23, 2018; DOI: 10.3171/2017.12.PEDS17306. 

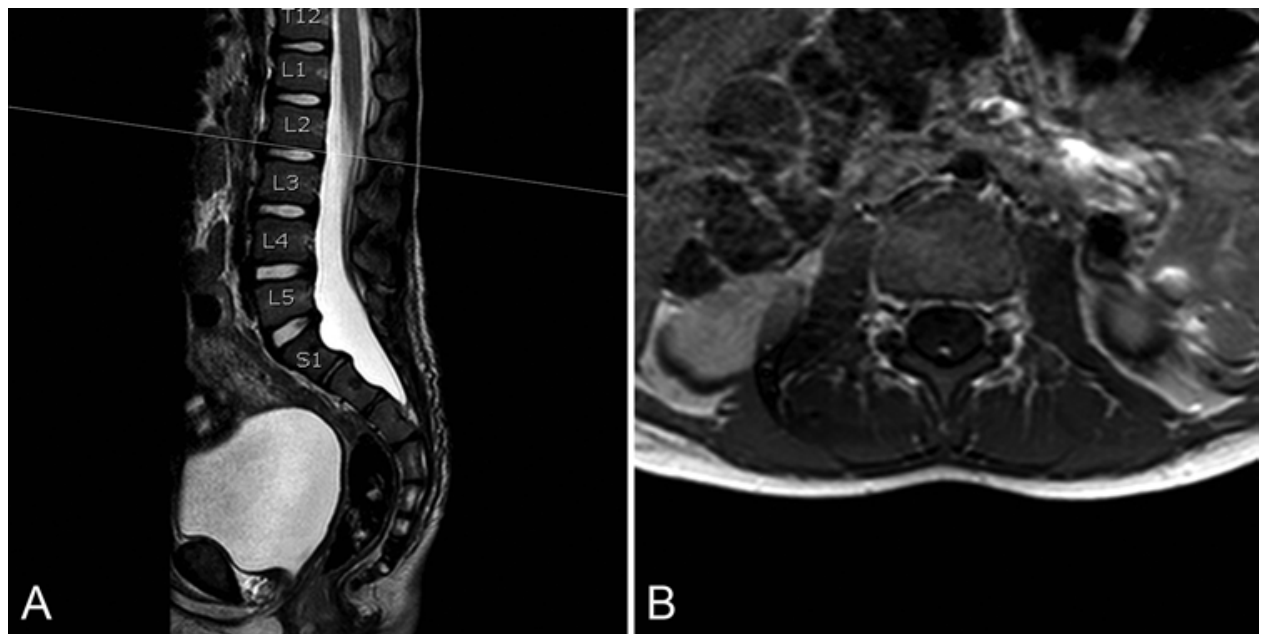

FIG. 1. A: Sagittal T2-weighted MR image showing that the conus medullaris is level with the L2-3 disc. B: High signal intensity on an axial T1-weighted MR image demonstrating the presence of a filum lipoma.

Here, we report our institutional (tertiary care pediatric hospital) experience and review the clinical presentation, radiological findings, and histopathological features of pediatric patients with NF and a symptomatic TC, and we discuss the association between NF and symptomatic TC that we found. We also define the incidence of TC in pediatric patients with NF to better inform patients and their families and clinicians who treat such patients.

\section{Methods}

In accordance with an institutional review board-approved protocol, with a waiver of consent, electronic medical records were reviewed retrospectively to determine the occurrence of TC surgery over a 10-year span (20062015). We also searched electronic medical records over the same time period to identify pediatric patients $(<18$ years of age) with an International Classification of Diseases, Ninth Revision (ICD-9) code for NF1 or NF2 who were seen at any OHSU facility. Then, we cross-referenced the records of patients who underwent surgical treatment for a TC, NF1, and/or NF2 with the records of patient visits in the pediatric neurosurgery outpatient clinic during the same time period.

For identified patients with NF, the following information was collected: age; sex; NF type; presenting complaints; results of musculoskeletal, urological, neurological, and gait examinations; pain status; presence of scoliosis; conus medullaris level; presence of a syrinx; presence of a filum lipoma or other tethering element; and operations performed for detethering, along with operative and pathological findings, complications (if relevant), and postoperative course. Additional data were collected for each patient with a diagnosis of NF1 or NF2 who underwent TC-release surgery and/or who had an ICD-9 diagnosis of TC, including the results of urodynamic testing if performed.

The exact position of the conus medullaris was determined by reviewing radiology reports and through direct review of axial and sagittal T1- and T2-weighted MR images by a board-certified pediatric neurosurgeon (N.R.S.,
L.C.B., or C.M.S.) (Fig. 1). The presence of a filum lipoma was determined by high signal intensity on multiple T1weighted axial MR images through the filum terminale and confirmation on the sagittal midline image. The presence of a syrinx was determined by the finding of T2-weighted hyperintensity within the central spinal cord parenchyma on axial and sagittal images.

For the purposes of this investigation, we focused on lower-extremity motor abnormalities and toe walking or other forms of abnormal gait or a regression in lower-extremity coordination over time. The musculoskeletal evaluations included an assessment of Achilles tendon tension, leg-length, and calf and foot-size discrepancy. Urological evaluations included obtaining a history of any secondary or age-inappropriate incontinence and, in some cases, performing formal urodynamic studies.

An English-language PubMed literature search was undertaken to find any previous reports of the co-occurrence of spinal cord tethering and NF1 or NF2 (search terms included "tethered cord neurofibromatosis" and "neurofibromatosis lipoma").

\section{Results}

During the study time period, 447 pediatric patients with a diagnosis of NF1 or NF2 were evaluated within an OHSU clinic; 67 of these patients were seen in the pediatric neurosurgery clinic and are the subject of this study. A total of 424 pediatric patients underwent transection of the filum terminale for spinal cord detethering during this period. Eight patients with NF underwent surgery for a TC. We also included 1 additional patient with NF with a symptomatic TC who was recommended to undergo surgery but instead elected expectant management with clinical follow-up. Thus, 9 (13\%) of the 67 patients with NF seen in the pediatric neurosurgery clinic over a 10 -year period presented with a symptomatic TC, and $8(12 \%)$ underwent TC-release surgery. All the patients diagnosed with both NF and a TC were seen in the pediatric neurosurgery outpatient clinic.

Four (44\%) of the 9 patients with NF and a symptom- 
TABLE 1. Patient demographics, radiological findings, clinical symptoms, and histopathological results

\begin{tabular}{|c|c|c|c|c|c|c|c|}
\hline $\begin{array}{l}\text { Pt } \\
\text { No. }\end{array}$ & $\begin{array}{c}\text { Age } \\
\text { (yrs), } \\
\text { Sex }\end{array}$ & Op & $\begin{array}{l}\text { Conus } \\
\text { Level }\end{array}$ & $\begin{array}{l}\text { Additional } \\
\text { Imaging } \\
\text { Finding(s) }\end{array}$ & Clinical Symptom(s) & $\begin{array}{c}\text { NF } \\
\text { Type(s) }\end{array}$ & Histopathological Result \\
\hline 1 & $5, \mathrm{~F}$ & Yes & L1-2 & Syrinx, fatty filum & Toe walking & 1 & Dense fibrous connective tissue \\
\hline 2 & $8, M$ & Yes & L2-3 & None & Toe walking, bowel \& bladder dysfunction & $1 \& 2$ & Dense fibrous connective tissue \\
\hline 3 & $4, M$ & Yes & $\mathrm{L}-2$ & None & Bladder dysfunction, progressive in-turning toes & 1 & Dense fibrous connective tissue \\
\hline 4 & $13, \mathrm{~F}$ & Yes & $L-3$ & None & Bladder dysfunction, refractory pain & 1 & Dense fibrous connective tissue \\
\hline 5 & $7, \mathrm{M}$ & Yes & L1-2 & Fatty filum & $\begin{array}{l}\text { Tight Achilles tendons, regressive neuromotor function } \\
\quad \& \text { coordination }\end{array}$ & 1 & $\begin{array}{l}\text { Dense fibrous connective tissue, } \\
\text { fibroadipose tissue }\end{array}$ \\
\hline 6 & $12, \mathrm{~F}$ & Yes & Low L-2 & Syrinx, scoliosis & Refractory pain \& numbness, bladder dysfunction & 1 & Dense fibrous connective tissue \\
\hline 7 & $5, \mathrm{M}$ & No & L2-3 & Syrinx, fatty filum & Regressive neuromotor function \& coordination & 1 & Not available \\
\hline 8 & $14, \mathrm{~F}$ & Yes & L2-3 & Syrinx, scoliosis & $\begin{array}{l}\text { Regressive neuromotor function \& coordination, bladder } \\
\text { dysfunction, refractory pain }\end{array}$ & 1 & Dense fibrous connective tissue \\
\hline 9 & $7, \mathrm{M}$ & Yes & L-3 & None & Clonus \& in-turning toes, hyperreflexia & 1 & Dense fibrous connective tissue \\
\hline
\end{tabular}

$\mathrm{Pt}=$ patient.

atic TC were female, and the mean age of the 9 patients was 8 years (range $4-14$ years); 8 patients had NF1 and 1 had both NF1 and NF2 according to review by OHSU genetic specialists. The radiological and clinical symptoms of each patient are summarized in Table 1. The position of the conus medullaris ranged from L1-2 to L-3. Three patients (33\%) had a filum lipoma, 4 (44\%) had a syrinx found radiologically, and 2 (22\%) had scoliosis. Using a mid-L-2 position as the cutoff, only 2 patients had a normal-level conus medullaris, but both of them had additional imaging abnormalities indicative of a TC (fatty filum terminale with or without a syrinx). Six patients had a low conus medullaris position, and 3 of them had additional radiological abnormalities. One patient had a borderline conus medullaris position (L-2) and no other radiological abnormalities (Table 1).

All 9 patients presented with neuromotor, skeletal, voiding, and/or pain-related symptoms. Five patients were noted to have bladder symptoms, 3 had refractory pain, 2 had a toe-walking gait, 3 had regressive neuromotor function and coordination, 1 had tight Achilles tendons, and 1 had new ankle clonus and hyperreflexia. Two patients underwent formal urodynamic testing; one had documented detrusor dysfunction with abnormal electromyographic activity, and the other had a large bladder capacity without contraction.

Histopathological examination of the filum terminale for the 8 patients who underwent surgery revealed dense fibroconnective tissue and blood vessels; fibroadipose tissue was found in 1 specimen.

A PubMed literature search revealed no previous reports of the co-occurrence of spinal cord tethering and NF1 or NF2.

In the 8 patients who underwent surgery, TC symptoms improved to various degrees. Three patients experienced complete resolution of their back pain and lower-extremity symptoms, and 5 patients reported improvement in their symptoms. The 1 patient who presented with new ankle clonus and hyperreflexia experienced resolution of these symptoms. Of the 5 patients who presented with urinary dysfunction, 3 experienced complete resolution of their symptoms, and 1 patient reported improved symptoms. The patient who had a large bladder capacity without contraction based on urodynamic testing did not report improvement in urinary symptoms. One patient initially experienced improvement in coordination and bladder dysfunction but developed new bilateral lower-extremity numbness 7 years later. Subsequent MR images revealed retethering, and the patient underwent a repeat TC-release surgery, which resolved his lower-extremity numbness.

\section{Discussion}

Although no pathophysiological relationship between them is known, the results presented here suggest an association between spinal cord tethering and NF in the pediatric patients who presented to our tertiary care pediatric hospital. This represents the first report in the English literature of an association between tethered spinal cord and NF. We propose that providers consider a diagnosis of TC when evaluating patients with NF. We recommend clinical screening by obtaining a history and performing a physical examination for patients with NF to detect any obvious symptoms and findings of a TC that, if present, should prompt MRI of the total spine. It should be noted that spinal MRI in patients with NF and spinal cord-related symptomatology is already advisable for ruling in or out a diagnosis of compressive neoplastic pathology.

Although 1 patient in this study with a TC was diagnosed with NF2, in addition to NF1, no patient with an isolated diagnosis of NF2 had a TC, which implies that the association reported here might be specific to NF1.

Although no pathophysiological mechanism linking $\mathrm{NF}$ and TC is known, we presume that the neural crest abnormalities caused by defects in the NF1 gene also increase the risk of filar abnormalities that result in a TC. ${ }^{3}$ NF1 is expressed variably, which suggests that undisclosed specifics of the NF-related genetic error determine the risk of a TC in each patient.

Limitations to this study include its retrospective nature and performance at a single institution. Given their propensity to form spinal masses, patients with NF are 
more likely than those in the general population to undergo complete neuraxis imaging. For these reasons, spinal imaging in asymptomatic patients might not be beneficial. Although it is possible also that an increased incidence of TC is a generalized feature of a broader range of neurodevelopmental disorders, we did not seek relevant data to answer that question.

We considered the alternative hypothesis that TC and NF randomly co-occurred in these patients, who presented to a pediatric neurosurgical practice that is attuned to diagnosing both conditions. However, the literature suggests that the rate of such incidental discovery of radiological spinal cord tethering is less than $1.5 \% .^{2,4}$

\section{Conclusions}

Despite the lack of any known pathophysiological relationship between NF and TC, the incidence of a symptomatic TC in patients with NF presenting for any reason to a single tertiary care pediatric neurosurgery clinic was $13 \%$. Counseling patients and families regarding TC symptomatology might be indicated in this patient population, as would total-spine MRI in symptomatic patients.

\section{Acknowledgments}

We thank Shirley McCartney, $\mathrm{PhD}$, for editorial assistance.

\section{References}

1. Allen RM, Sandquist MA, Piatt JH Jr, Selden NR: Ultrasonographic screening in infants with isolated spinal strawberry nevi. J Neurosurg 98 (3 Suppl):247-250, 2003

2. Cools MJ, Al-Holou WN, Stetler WR Jr, Wilson TJ, Muraszko KM, Ibrahim M, et al: Filum terminale lipomas: imaging prevalence, natural history, and conus position. J Neurosurg Pediatr 13:559-567, 2014

3. Gutmann DH, Ferner RE, Listernick RH, Korf BR, Wolters PL, Johnson KJ: Neurofibromatosis type 1. Nat Rev Dis Primers 3:17004, 2017

4. Kesler H, Dias MS, Kalapos P: Termination of the normal conus medullaris in children: a whole-spine magnetic resonance imaging study. Neurosurg Focus 23(2):E7, 2007

5. Kresak JL, Walsh M: Neurofibromatosis: a review of NF1, NF2, and schwannomatosis. J Pediatr Genet 5:98-104, 2016

6. O'Neill BR, Gallegos D, Herron A, Palmer C, Stence NV, Hankinson TC, et al: Use of magnetic resonance imaging to detect occult spinal dysraphism in infants. J Neurosurg Pediatr 19:217-226, 2017

7. Sasani M, Asghari B, Asghari Y, Afsharian R, Ozer AF: Correlation of cutaneous lesions with clinical radiological and urodynamic findings in the prognosis of underlying spinal dysraphism disorders. Pediatr Neurosurg 44:360-370, 2008

8. Selden NR, Nixon RR, Skoog SR, Lashley DB: Minimal tethered cord syndrome associated with thickening of the terminal filum. J Neurosurg 105 (3 Suppl):214-218, 2006

9. Thompson EM, Strong MJ, Warren G, Woltjer RL, Selden NR: Clinical significance of imaging and histological characteristics of filum terminale in tethered cord syndrome. $\mathbf{J}$ Neurosurg Pediatr 13:255-259, 2014

10. Tsirikos AI, Saifuddin A, Noordeen MH: Spinal deformity in neurofibromatosis type-1: diagnosis and treatment. Eur Spine J 14:427-439, 2005

\section{Disclosures}

The authors report no conflict of interest concerning the materials or methods used in this study or the findings specified in this paper.

\section{Author Contributions}

Conception and design: Selden, Baird. Acquisition of data: Quinsey, Krause. Analysis and interpretation of data: all authors. Drafting the article: all authors. Critically revising the article: all authors. Reviewed submitted version of manuscript: all authors. Approved the final version of the manuscript on behalf of all authors: Selden.

\section{Correspondence}

Nathan R. Selden: Oregon Health \& Science University, Portland, OR.seldenn@ohsu.edu. 